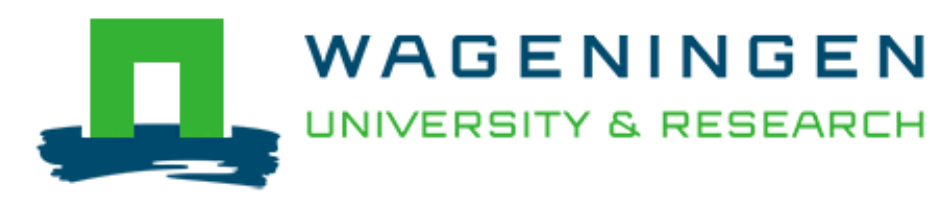

Genetically engineering Crambe abyssinica- A potentially high-value oil crop for salt land improvement

Qi, W., Tinnenbroek-Capel, I. E. M., Salentijn, E. M. J., Zhang, Z., Huang, B., Cheng, J., ... van Loo, E. N.

This article is made publically available in the institutional repository of Wageningen University and Research, under article 25fa of the Dutch Copyright Act, also known as the Amendment Taverne.

Article 25 fa states that the author of a short scientific work funded either wholly or partially by Dutch public funds is entitled to make that work publicly available for no consideration following a reasonable period of time after the work was first published, provided that clear reference is made to the source of the first publication of the work.

For questions regarding the public availability of this article, please contact openscience.library@wur.nl.

Please cite this publication as follows:

Qi, W., Tinnenbroek-Capel, I. E. M., Salentijn, E. M. J., Zhang, Z., Huang, B., Cheng, J., ... van Loo, E. N. (2018). Genetically engineering Crambe abyssinica- A potentially high-value oil crop for salt land improvement. Land Degradation and Development, 29(4), 1096-1106. https://doi.org/10.1002/Idr.2847 


\title{
Genetically engineering Crambe abyssinica-A potentially high-value oil crop for salt land improvement
}

\author{
Weicong $\mathbf{Q i}^{1,2,3}$ (D) । Iris E. M. Tinnenbroek-Capel ${ }^{2}$ | Elma M. J. Salentijn ${ }^{2}$ | Zhao Zhang ${ }^{4}$ (D) । \\ Bangquan Huang $^{5}$ | Jihua Cheng ${ }^{2,6}$ | Hongbo Shao ${ }^{1}$ (D) । Richard G. F. Visser ${ }^{2}$ । \\ Frans A. Krens ${ }^{2}$ । Eibertus N. Van Loo ${ }^{2}$
}

${ }^{1}$ Salt-soil Agricultural Center, Institute of Agricultural Resources and Environment, Jiangsu Academy of Agricultural Sciences, Nanjing 210014, PR China

${ }^{2}$ Laboratory of Plant Breeding, Wageningen University and Research Centre, PO Box 386, Wageningen, Gelderland 6700, The Netherlands

${ }^{3}$ Key Laboratory of Oil Crops in Huanghuaihai Plain, Ministry of Agriculture, P.R. China, Henan Provincial Key Laboratory for Oil Crops Improvement

${ }^{4}$ Beijing Key Laboratory of Development and Quality Control of Ornamental Crops,

Department of Ornamental Horticulture, China Agricultural University, Beijing 100193, PR China

${ }^{5}$ College of Life Sciences, Hubei University, Wuhan 430062, PR China

${ }^{6}$ Life Science and Technology Center, China Seed Group Co. Ltd., Wuhan 430000, PR China

Correspondence

W. Qi, Salt-soil Agricultural Center, Institute of Agricultural Resources and Environment, Jiangsu Academy of Agricultural Science, Nanjing 210014, PR China.

Email: weicong_qi@163.com

E. N. Van Loo, Laboratory of Plant Breeding, Wageningen University and Research Centre, PO Box 386, Wageningen, Gelderland 6700 , The Netherlands.

Email: robert.vanloo@wur.nl

\begin{abstract}
Crambe abyssinica (crambe) is a new industrial oil crop that can grow on saline soil and tolerates salty water irrigation. Genetically engineered crambe in which the seed-oil composition is manipulated for more erucic acid and less polyunsaturated fatty acid (PUFA) would be highly beneficial to industry. In this research, lysophosphatidic acid acyltransferase 2 RNA interference (CaLPAT2-RNAi) was introduced into the crambe genome to manipulate its oil composition. The result showed in comparison with wild type, CaLPAT2-RNAi could significantly reduce linoleic and linolenic acid content, simultaneously increasing erucic acid content. Systematic metabolism engineering was then carried out to further study CaLPAT2-RNAi, combined with the overexpression of Brassica napus fatty acid elongase (BnFAE), Limnanthes douglasii LPAT (LdLPAT), and RNAi of endogenous fatty acid desaturase 2 (CaFAD2-RNAi). Oil composition analysis on the tranformants' seeds showed that (a) with CaFAD2-RNAi, PUFA content could be dramatically decreased, in comparison with BnFAE + LdLPAT + CaFAD2-RNAi, and BnFAE + LdLPAT + CaFAD2-RNAi + CaLPAT2-RNAi seeds showed lower linolenic acid content; (b) BnFAE + LdLPAT + CaFAD2-RNAi + CaLPAT2-RNAi could increase the erucic acid content in crambe seed oil from less than $66.6 \%$ to $71.6 \%$, whereas the highest erucic acid content of BnFAE + LdLPAT + CaFAD2-RNAi was 79.2\%; (c) although the four-gene combination could not increase the erucic acid content of seed oil to a higher level than the others, it led to increased carbon resource deposited into C22:1 and C18:1 moieties and lower PUFA. Summarily, the present research indicates that suppression of LPAT2 is a new, promising strategy for seed-oil biosynthesis pathway engineering, which would increase the value of crambe oil.
\end{abstract}

\section{KEYWORDS}

Crambe abyssinica, lysophosphatidic acid acyltransferase, metabolism pathway regulation, oil, salt land improvement

\section{1 | INTRODUCTION}

The oil stored in plant seeds (mostly as triacylglycerol [TAG]) is not only a crucial nutrition for seedling growth (Carlsson, 2009; Chapman \& Ohlrogge, 2012; Gurr et al., 1974) but also an essential renewable resource for humans. Oil seed crop cultivation is an important part of global agriculture. Erucic acid (omega-9 C22:1 fatty acid) is a very important lipid compound produced by plants. Erucic acid and its derivatives, such as erucamide, behenic acid, or alcohol, have wide industrial uses as, for example, surfactants, lubricants, and pour point depressants (Rudloff \& Wang, 2011; Vargas-Lopez, Wiesenborn, Tostenson, \& Cihacek, 1999). Erucic acid only occurs in the seed oil of the plant families Brassicaceae and Tropaeolaceae. The oil seed plant Crambe abyssinica (crambe), which is of Brassicaceae family and also known as Abyssinian mustard, Abyssinian kale, colewart, or datran, is a new crop usually cultivated to produce high erucic acid plant oil and other valuable chemical compounds for industry (Bruun \& Matchett, 1963; White \& Higgins, 1966). Crambe is a low-input crop and grows well on all soil types from heavy clays to light sands and is tolerant to salinity and several other kinds of abio-stress (Falasca, 
Flores, Lamas, Carballo, \& Anschau, 2010; Fowler, 1991; Vasconcelos, Chaves, Souza, Gheyi, \& Fernandes, 2015). It could be cultivated on saline soil and tolerant to salty water irrigation. Therefore, it can be used as an alternative crop in marginal areas near coastlines for salt land improvement (Falasca et al., 2010). Increasing the erucic content in crambe seed oil and decreasing the polyunsaturated fatty acids (PUFAs) by breeding or genetic engineering could intensively elevate the economic value of this crop (Falasca et al., 2010).

Erucic acid is produced by ketoacyl-CoA synthase (FAE) of cytosol fatty acid elongase complex from C18:1 CoA in the developing seed embryo of Brassicaceae plants. Subsequently, erucic CoA is integrated into the glycerol backbone by the acyltransferase of the Kennedy pathway that takes place in the endoplastic reticulum (Kennedy, 1961; Murphy \& Vance, 1999). In the first two steps, glycerol-3-phosphate is acylated by glycerol-3-phosphate acyltransferase into lysophosphatidic acid (Murata \& Tasaka, 1997; Zheng \& Zou, 2001), and it is then acylated further by lysophosphatidic acid acyltransferase (LPAT) into phosphatidic acid (Khaik-Cheang and Huang, 1989; Kim, Li, \& Huang, 2005; Soupene, Fyrst, \& Kuypers, 2007). This is followed by dephosphorylation of phosphatidic acid catalysed by phosphatidate phosphatase to release diacylglycerol (DAG; Kocsis, Weselake, Eng, Furukawa-Stoffer, \& Pomeroy, 1996). The final acylation of DAG, catalysed by diacylglycerol acyltransferase (DGAT; Cases et al., 1998; Routaboula, Benningb, Bechtoldc, Cabochea, \& Lepinieca, 1999), generates TAG that is transferred to oil bodies for storage (Huang, 1996; Murphy \& Vance, 1999). The catalysis of C18:1 CoA to PUFA (i.e., linoleic acid and linolenic acid) by $F A D$ is a well-known substrate-competition to erucic acid biosynthesis (Cheng et al., 2013; Jadhav et al., 2005; Okuley et al., 1994).

High erucic acid vegetable oil is that which contains over $55 \%$ erucic acid, and this is a valuable feedstock for the chemical industry. Nowadays, most high erucic acid vegetable oil supplied to the chemical industry comes from high erucic acid rapeseed (HEAR). The cultivation of HEAR, however, is problematic because of the risk of contaminating food quality rapeseed (Canola) by either inadvertent mixing or crosspollination. Therefore, HEAR cultivars are cultivated in Europe (about 40,000 hectares in 2006/2007) and in the USA and Canada as an identity-preserved crop, because oil from HEAR (high erucic acid rapeseed oil, HERO) should not enter the food chain. The upper limit of erucic acid in food oil rapeseed has been set to $5 \%$ in the EU (Council Directive 76/621/EEC), although the risk of erucic acid consumption was only inferred from effects on rats and in humans, no epidemiological evidence is available that erucic acid consumption leads to an increase in cardiovascular diseases (Hu, Sullivan-Gilbert, Gupta, \& Thompson, 2006; Schierholt, Becker, \& Ecke, 2000). For infant formulas, EC Directive 2006/141/EC (2006) states a limit of $1 \%$ erucic acid of total fatty acids. Because of the health risk, another member of the Brassicaceae family, C. abyssinica (crambe) is considered as a candidate to substitute HEAR for high erucic acid vegetable oil production (Bruun \& Matchett, 1963; Rudloff \& Wang, 2011). The main advantages of crambe, with regards to the risk of erucic acid vegetable oil entering the food chain are (a) identity preservation is easy as it is morphologically very distinct from rapeseed, both as a crop and as seed; (b) it does not outcross with rapeseed as HEAR can with Canola. Technically, crambe also has advantages over HEAR as it has a higher erucic acid content (59-65\%) in its seed oil than HEAR (50-55\%); and (c) the oil contains relatively less
PUFAs, which could benefit the downstream process of erucic acid isolation.

As a crop of bio-based economic value, crambe could become even more attractive to farmers and end users if crambe seed oil fatty acid composition could be optimized further, for instance, increasing erucic acid content, decreasing PUFA content, and so forth. The content of erucic acid in the seed oil of crambe can be up to 65\% depending on growth conditions and cultivars and has almost reached its maximum. Enzymatic analysis on Brassicaceae developing seeds shows that the LPAT2 enzyme in charge of catalysing the incorporating of fatty acids into triglycerides on the sn- 2 position cannot use erucic acid as a substrate (Kuo \& Gardner, 2002). This means erucic acid can only be incorporated on the sn-1 and sn-3 positions of glycerol and not on the sn-2 position of triglycerides, which limits the potential erucic acid content in Brassicaceae crop seed oil to $66.7 \%(2 / 3)$. Because of this, genetic modification strategies have been developed to enable incorporating erucic acid on the sn- 2 position by introducing a Limnanthes douglasii LPAT (LdLPAT) that takes erucic acid as a substrate for lysophosphatidate sn-2 acylation (Cao, Khaik-Cheang, \& Huang, 1990; Lassner, Levering, Davies, \& Knutzon, 1995; Laurent \& Huang, 1992). Previous research on Brassica napus (Han et al., 2001) and crambe (Li et al., 2012) shows that erucic acid levels could be elevated by introducing the LdLPAT gene, $B$. napus fatty acid elongase (ketoacylCoA synthase, BnFAE), which is in charge of prolonging oleic acid into erucic acid (Mietkiewska, Brost, Giblin, Barton, \& Taylor, 2007), and the RNAi sequence targeted at native fatty acid desaturase 2 (CaFAD2-RNAi), which is in charge of desaturating oleic acid into linoleic acid and linolenic acid (Cheng et al., 2013). In the present study, endogenous LPAT (CaLPAT2) suppression was engaged into the new approach with the aim of manipulating crambe seed oil composition by genetic modification. First, an RNA interference construct (CaLPAT2-RNAi; Wesley et al., 2003) was developed to target a conserved sequence of LPAT2 of crambe as well as that of other Brassicaceae species. CaLPAT2-RNAi was then combined with BnFAE, LdLPAT, and CaFAD2-RNAi into one vector that was engaged to regulate oil compounds in crambe seeds. Simultaneously, vectors of BnFAE + LdLPAT and BnFAE + LdLPAT + CaFAD2-RNAi were also transformed into crambe for comparison.

\section{I MATERIALS AND METHODS}

\section{1 | Vectors used in present approach}

As shown in Figure 1, four binary vectors were used in this study. The vector CaLPAT-RNAi was composed of the RNA interference gene against CaLPAT2, which was controlled by the $35 \mathrm{~S}$ promoter and terminator. The BnFAE + LdLPAT and BnFAE + LdLPAT + CaFAD2-RNAi vectors were acquired from the Unit of Botany, Aachen University of Technology. The BnFAE + LdLPAT vector carries two genes, LdLPAT and BnFAE and BnFAE + LdLPAT + CaFAD2-RNAi contains LdLPAT, BnFAE, and CaFAD2-RNAi. The BnFAE + LdLPAT + CaFAD2-RNAi + CaLPAT2RNAi construct containing LdLPAT, BnFAE, CaFAD2-RNAi, and CaLPAT2-RNAi was acquired after the molecular modification of 
(a) CaLPAT2-RNAi

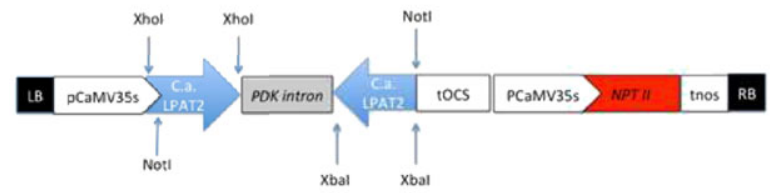

(b) BnFAE+LdLPAT+CaFAD2-RNAi+CaLPAT2-RNAi
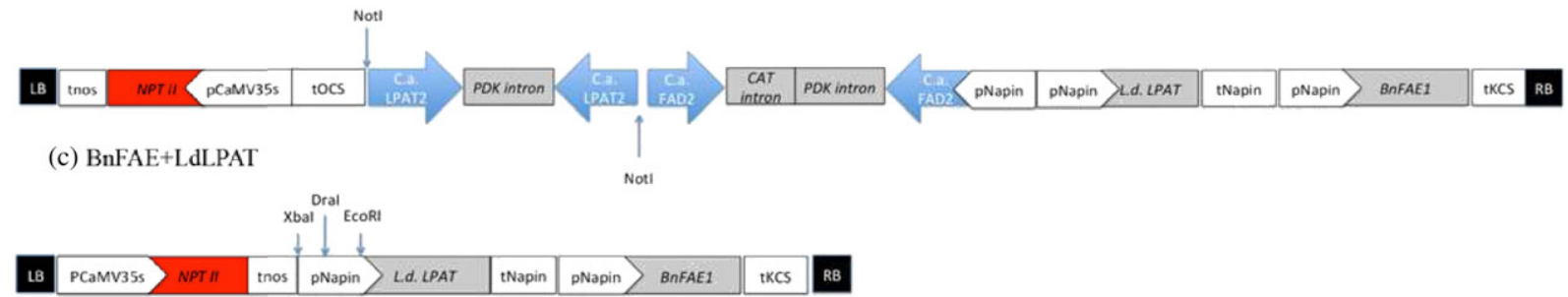

(d) BnFAE + LdLPAT + CaFAD2-RNAi

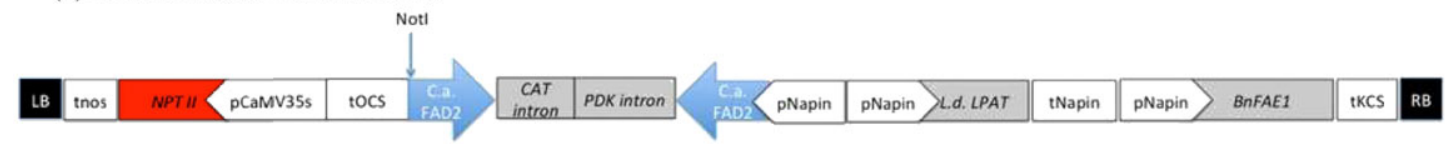

FIGURE 1 The functional genes contained by the four vectors used in the present research: Four vectors were used in this study. All have NPTII as the selectable marker for plant transformation. In CaLPAT2-RNAi vector (a) the CaLPAT2 RNAi was controlled by pCaMV35s promoter. In the other vectors, genes adjusting plant seed oil composition in BnFAE + LdLPAT + CaFAD2-RNAi + CaLPAT2-RNAi, (b) BnFAE + LdLPAT (c), and $\mathrm{BnFAE}+\mathrm{LdLPAT}+\mathrm{CaFAD2}-\mathrm{RNAi}(\mathrm{d})$ were ruled by Brassica napus Napin promoter (pNapin). $\mathrm{LB}=$ left border; RB = right border; tnos = NOS terminator; tOCS = OCS terminator; tKCS = KCS terminator) [Colour figure can be viewed at wileyonlinelibrary.com]

BnFAE + LdLPAT + CaFAD2-RNAi. Functional genes in BnFAE + LdLPAT, BnFAE + LdLPAT + CaFAD2-RNAi, and BnFAE + LdLPAT + CaFAD2RNAi + CaLPAT2-RNAi were controlled by the Napin promoter. All of those vectors contained the NPTII gene as a selectable marker. For inoculating plants, CaLPAT-RNAi, BnFAE + LdLPAT + CaFAD2RNAi + CaLPAT2-RNAi, and BnFAE + LdLPAT + CaFAD2-RNAi were transformed into agrobacterium strain AGL1, whereas BnFAE + LdLPAT was introduced in AGLO (Lazo, Stein, \& Ludwig, 1991).

\section{2 | Construction of CaLPAT-RNAi vector}

The target coding region of CaLPAT2 was cloned from cDNA of developing seeds ( 20 days after pollination) of $C$. abyssinica cv. Galactica by polymerase chain reaction (PCR) using specific primers (forward primer: CACC-GGGTAAAGAACATGCTCTTG and reverse primer: AGTTTA GCCTCAGTAAATCG, designed according to the CDNA sequence of crambe LPAT2 acquired from NCBI, GI: 124378834; Figure 2). The amplicon was verified by sequencing and then ligated into donor vector pENTR/D-TOPO using the Gateway ${ }^{\circledR}$ BP ClonaseTM II enzyme mix (Invitrogen) to construct entry vector pENTR/D-TOPO::CaLPAT2. The target fragment in the entry vector was subsequently exchanged into Gateway destination vector pHellsgate 8 (Wesley et al., 2003) using the Gateway LR® ClonaseTM II enzyme mix (Invitrogen). Both constructs were transformed into Escherichia coli (strain: TOP10, Invitrogen, Cat. no. 4040-50) for amplification. The transformants of pENTR/D-TOPO::CaLPAT2 were checked by colony PCR analysis using primers M13 forward and reverse (GTAAACGACGGCCAG and CAGG AAACAGCTATGAC). The transformants of pHellsgate CaLPAT2-RNAi were checked by restrictions of Xbal and Xhol, respectively. Finally, the accurate pHellsgate-CaLPAT2-RNAi construct was transformed into Agrobacterium tumefaciens strain AGL1 by electroporation.

\section{3 | Modifying BnFAE + LdLPAT + CaFAD2-RNAi into BnFAE + LdLPAT + CaFAD2-RNAi + CaLPAT2- RNAi}

As shown in Figure 1, in the DNA molecule of BnFAE + LdLPAT + CaFAD2-RNAi, there is only one restriction site of Notl restriction enzyme in the connection region of CaFAD2-RNAi palindromic sequence to the Napin promoter; and in the DNA molecule of pHellsgate CaLPAT-RNAi, there are two Notl restriction sites between which the palindromic sequence of CaLPAT-RNAi is located.

The pHellsgate CaLPAT-RNAi vector DNA was digested by Notl. The digested DNA fragments were then separated by electrophoresis with $0.8 \%$ agarose gel, by which the desired palindromic fragment (364 BP) was separated. After reclaiming the fragment from the gel, it was ligated with the linear BnFAE + LdLPAT + CaFAD2-RNAi molecule cut by Notl. From the modification, the BnFAE + LdLPAT + CaFAD2RNAi + CaLPAT2-RNAi vector was constructed. In this new vector, there are two palindrome structures (CaFAD2-RNAi and CaLPAT2-RNAi) side-by-side, sharing the same promoter (Napin) and terminator (tOCS). The ligation product was transformed into E. coli competent cells (strain: TOP10 Chemical, Invitrogen) by electroporation. Candidate colonies' plasmid DNA was isolated and digested again by Notl. Those giving a unique band of the original size (364 BP) were chosen for transforming agrobacterium strain AGL1.

\section{4 | Plant transformation}

C. abyssinica seeds (cv. Galactica, harvested July 2009 from a seed production field in Wageningen, The Netherlands) were germinated to obtain cotelydonary node explants as starting material for 


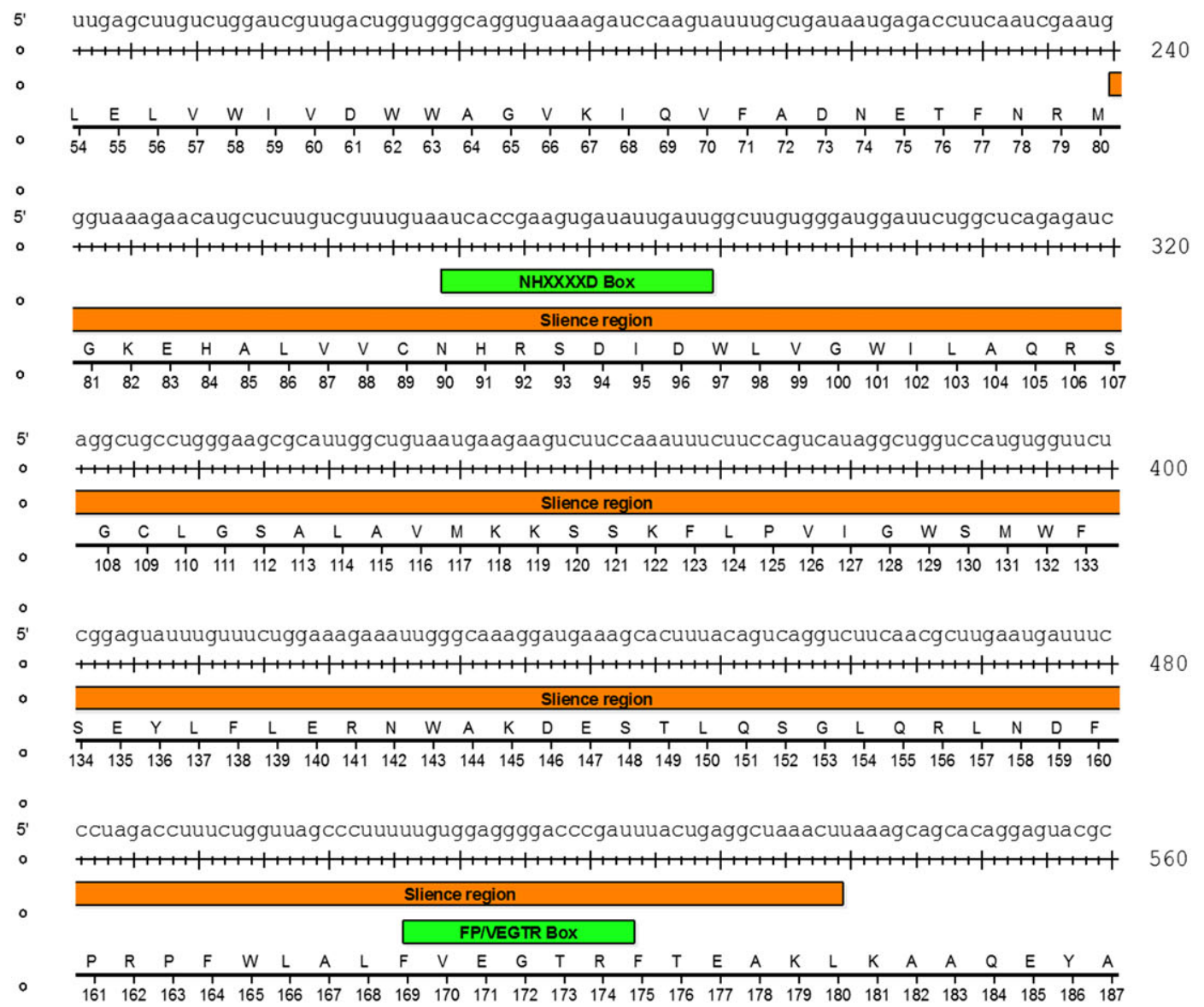

(a)

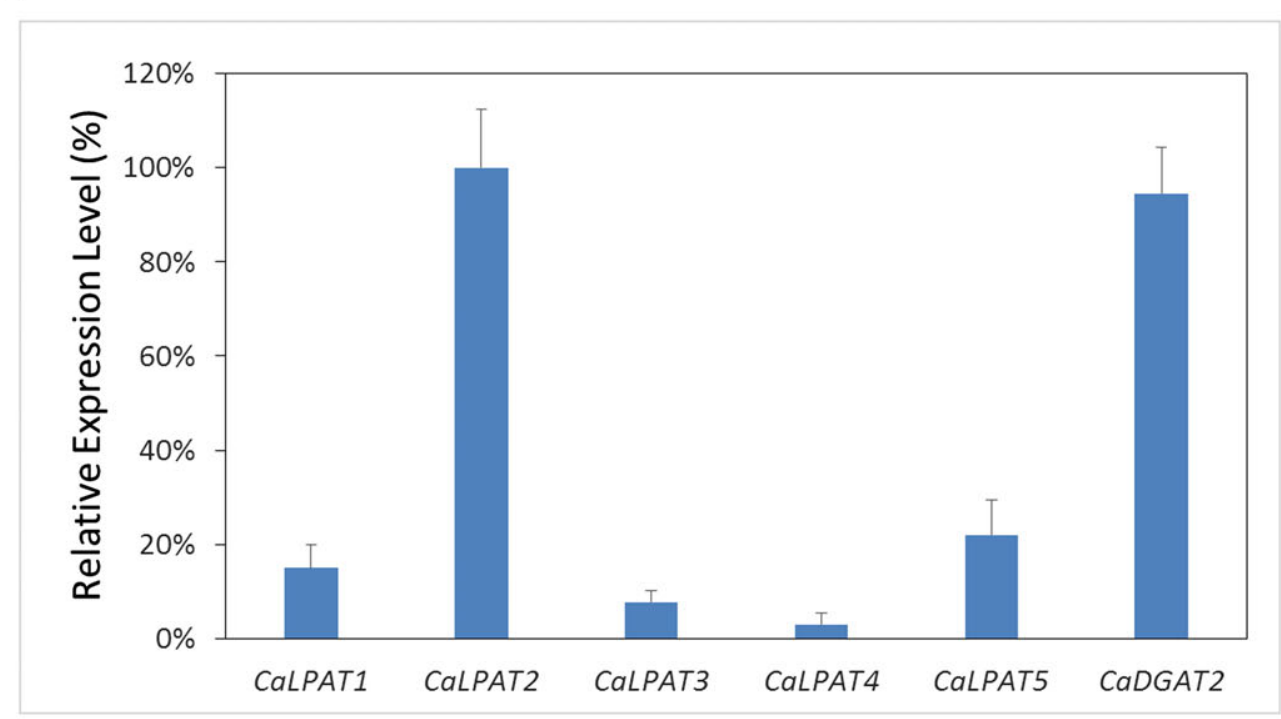

(b)

FIGURE 2 (a) The target sequence picked up for Crambe abyssinica endogenous LPAT2 RNAi: A segment of mRNA of C. abyssinica LPAT2 and the corresponding peptide is displayed in the chart. The orange bar marks the whole sequence ( $360 \mathrm{BP}$ ) later incorporated into the RNAi vector, and the two green bars show two conserved regions, the NHXXXD box and FP/VEGTR box. (b) The expression level of Arabidopsis LAPT 1-5 homologous genes of crambe in the developing seeds: The expression level of Arabidopsis LPAT1-5 homologous genes of C. abyssinica in the developing seeds 20 days after flowering was assayed by quantitative polymerase chain reaction. The results showed that LPAT2 had the strongest expression that was 7 to 20 folds higher than the others. The expression level of Arabidopsis diacylglycerol acyltransferase 2 homologues in the same period was as same as CaLAPT2. WT = wild type [Colour figure can be viewed at wileyonlinelibrary.com]

transformation and regeneration. The in vitro material was cultivated in growth chambers with a photoperiod of $16 \mathrm{hr}$ with a light intensity of $33 \mu \mathrm{mol} \cdot \mathrm{m}^{2} \cdot \mathrm{s}^{-1}$ and a temperature of $24{ }^{\circ} \mathrm{C}$.
The transformation and selection for GM events of C. abyssinica in this chapter were performed as we described previously (Qi et al., 2014). 
Arabidopsis thaliana plants (Accession, Columbia) were grown in the greenhouse or in the climate chamber with the following settings: $22 / 19{ }^{\circ} \mathrm{C}$ with $70 \%$ relative humidity and $16 / 8 \mathrm{hr}$ day/night periods, respectively. If the light intensity dropped below $150 \mathrm{~W} \cdot \mathrm{m}^{-2}$, it was compensated with an extra $100 \mathrm{~W} \cdot \mathrm{m}^{-2}$ supplemental light. A. tumefaciens with target pHellsgate CaLPAT2-RNAi construct was used to transform Arabidopsis plants using the floral dip method (Clough \& Bent, 1998). Kanamycin selection of positive transformants was performed (Harrison et al., 2006).

\section{5 | Identifying transformants}

\subsection{1 | Southern blotting}

From BnFAE + LdLPAT TO candidate transformants genomic DNA was isolated from the leaf material of in vitro plants with the method described by Aldrich and Cullis (1993) but with $1 \%(w / v)$ polyvinylpyrrolidone-10 in the DNA extraction buffer. For each transformant, the DNA isolation was performed 3 times independently for each candidate. For each DNA isolation, $1 \mathrm{~g}$ fresh leaf material was used. Three pieces of DNA samples (40 $\mathrm{mg}$ per piece) from each candidate transformant were digested by EcoRI, Dral, and Xbal. TheT-DNA region of BnFAE + LdLPAT is shown in Figure 1. The NPTIl gene is located near the left border. The nearest restriction sites of EcoRI, Dral, and Xbal to the left border are also marked in Figure 1. For copy number determination, a probe (516 BP) was designed based on the sequence of the NPTII gene and was labelled with ${ }^{[32 \mathrm{P}]}$ ATP. The digested DNA samples were fractionated on a $0.8 \%(\mathrm{w} / \mathrm{v})$ agarose gel and transferred to Hybond $\mathrm{N}+$ membrane (Amersham Biosciences, UK) according to the manufacturer's recommendations. The membrane was hybridized at $65{ }^{\circ} \mathrm{C}$ overnight with $20 \mathrm{ng}$ of the nptll probe and washed for $2 \times 30$ min with $0.1 \times$ saline-sodium citrate buffer, $0.1 \%(w / v)$ SDS at $65{ }^{\circ} \mathrm{C}$. The DNA gel blots were exposed to a phosphorimager screen and subsequently scanned into a Bioimager device (Fujix BAS2000).

The primers of probe amplification were TCCAAGATGTAGCATC AAGAATCC (forward) and TGGTTTCGATCCACTTTCTTAC (reverse).

\section{PCR}

Genomic DNA was isolated from young leaves of each candidate TO plant with the same method as used for the Southern blotting. The
NPTII primers are used to identify the transgenic nature of candidate materials. The virG primers are used to amplify the virG gene from the vector backbone to test for its presence in the material. If the result of virG is positive, then the material cannot be counted as a GM candidate or moved into soil for seed ripening. They should remain in the medium with cefotaxime and timentin until such time that there are no longer positive PCR results for virG.

The primer sequences for NPTII were forward 5'- TGGGCACAA CAGACAATCGGCTGC-3' and reverse 5'-TGCGAATCGGGAGCGG CGATACCG-3' and for virG, forward 5'-GCCGGGGCGAGACCAT AGG-3' and reverse 5'-CGCACGCGCAAGGCAACC-3'.

\section{qPCR}

Two pairs of primers specific to the crambe LPAT2 genes were developed based on the cDNA sequences in C. abyssinica (GI: 124378834), and two pairs of primers of Arabidopsis LPAT2 gene were developed on the cDNA sequences of AtLPAT2 (GI:145339616). The gene $\beta$-actin 2 (Gl: 20465834) was used as a reference gene. These primers used in real-time PCR are listed in Table 1. The primers used to evaluate the expressions of Arabidopsis LPAT1, 3, 4, 5, and DGAT2 homologous genes in crambe were the same as previous reports (Kim et al., 2005; $\mathrm{Li}, \mathrm{Yu}, \&$ Hildebrand, 2010). To develop crambe seed RNA isolation, total RNA was extracted from bulked seeds of T0 plants (10 seeds per plant, 20 days after flowering [DAF]) with an RNeasy Plant Mini Kits (Qiagen, Germany) according to the manufacturer's instructions. For the leaf RNA isolation of crambe and Arabidopsis, total RNA was extracted form $0.5 \mathrm{~g}$ fresh leaf material from the greenhouse plant with the same kit. The isolated RNA was treated with RNase-free TURBO DNase (Ambion, USA) to remove residual genomic DNA. First-strand cDNA was synthesized in $20 \mu \mathrm{l}$ from $1 \mu \mathrm{g}$ of total RNA with an iScript ${ }^{\mathrm{TM}}$ cDNA Synthesis Kit (Bio-rad, USA). The cDNA samples were 20x diluted and used as templates for real-time PCR. The PCR reaction contains $2 \mu$ lemplates, $5 \mu$ I SYBR Green Super Mix (Bio-rad, USA), and $1 \mu \mathrm{l}$ of each of the forward and reverse primers $(3 \mu \mathrm{M})$, giving $10 \mu$ l. Cycling conditions were $1 \mathrm{cycle}$ at $95^{\circ} \mathrm{C}$ for $3 \mathrm{~min}$ followed by 30 cycles at $95^{\circ} \mathrm{C}$ for $10 \mathrm{~s}, 60^{\circ} \mathrm{C}$ for $1 \mathrm{~min}$, then a final melt step from $65^{\circ} \mathrm{C}$ to $95^{\circ} \mathrm{C}$ ramp with $0.5^{\circ} \mathrm{C}$ increments per cycle to monitor specificity. PCR reactions were performed in triplicate. The expression of each replicate was normalized by the reference gene, $\beta$-actin 2 , which has shown to be stably

TABLE 1 The quantitative polymerase chain reaction primers for testing LPAT2 expression levels in Arabidopsis leaf, crambe leaf, and crambe developing seeds

\begin{tabular}{|c|c|c|}
\hline Target gene & Primer name & Sequence \\
\hline & AtLPAT2_F1 & GGT GGT TGC AGA AAC CTT GT \\
\hline Arabidopsis LPAT2 & AtLPAT2_R1 & AGC ATG TTC TTT GCC CAT T \\
\hline \multirow[t]{2}{*}{ (GI:145339616) } & AtLPAT2_F2 & GGT GGT TGC AGA AAC CTT GT \\
\hline & AtLPAT2_R2 & GAG CAT GTT CTT TGC CCA TT \\
\hline Arabidopsis $\beta$-actin 2 (GI:20465834) & $\begin{array}{l}\text { AtActin2_F } \\
\text { AtActin2_R }\end{array}$ & $\begin{array}{l}\text { GATGGAGACCTCGAAAACCA } \\
\text { AAAAGGACTTCTGGGCACCT }\end{array}$ \\
\hline Crambe LPAT2 & CaLPAT2_F1 & CGC ATT GGC TGT AAT GAA GA \\
\hline \multirow[t]{3}{*}{ GI:124378834 } & CaLPAT2_F2 & CCA GTC ATA GGC TGG TCC AT \\
\hline & CaLPAT2_R1 & TTC ATC CTT TGC CCA ATT TC \\
\hline & CaLPAT2_R2 & CCA CAA AAA GGG CTA ACC AG \\
\hline \multirow[t]{2}{*}{ Crambe FAD2 } & CaFAD2-F1 & CCGTGAACGTCTCCAGATAT \\
\hline & CaFAD2-R1 & CGTTGACTATCAGAAGCCGA \\
\hline
\end{tabular}


expressed in crambe seedlings under arsenate stress and in various B. napus cultivars (Hu et al., 2009; Paulose, Kandasamy, \& Dhankher, 2010). The relative expression level of each replicate was calculated according to the comparative CT method (User Bulletin No. 2, ABI PRISM 7700 Sequence Detection System, December 1997; PerkinElmer, Applied Biosystems). The mean of three replicates represents the relative expression level of a line.

\subsection{2 | Gas chromatography analysis}

Gas chromatography (GC) was engaged to analyse the oil composition of crambe seed. The wild type (WT) seeds were acquired from the control plant through tissue culture together with the transformed and grew in the same conditions. An individual seed was crushed in a $1.5 \mathrm{ml}$ Eppendorf tube with $600 \mu \mathrm{l}$ of hexane to extract the oleic compositions (at room temperature). After centrifuging at $18,000 \mathrm{~g}$ for $5 \mathrm{~min}$, $200 \mu \mathrm{l}$ of the hexane supernatant was taken into the GC vial for triacylglycerol analysis by the high temperature column. Subsequently, $40 \mu \mathrm{l}$ methanol (with $5 \mathrm{M} \mathrm{KOH}$ ) was added into the Eppendorf tube, and the closed tube was incubated at $60^{\circ} \mathrm{C}$ with shaking to hydrolyse the TAG to obtain the free fatty acids and to methylate the fatty acids to fatty acid methyl esters (FAME). The FAME composition was determined using GC (column/DB-23, Agilent). A 1- $\mu$ l sample was injected into the GC with FID with a split ratio of 1:20. A temperature gradient was used starting with $10 \mathrm{~min}$ at $180^{\circ} \mathrm{C}$, a temperature increase to $240^{\circ} \mathrm{C}$ for $8 \mathrm{~min}$, and $7 \mathrm{~min}$ at $240^{\circ} \mathrm{C}$. Identification of FAME was based on retention time of standards and checked by separate GC-MS analysis using the same column and temperature profile. The relative amounts of different FAME were determined as the relative peak area of the components in the total peak area of FAME. Table 2 illustrates the quantity of seeds that were put into the GC FAME assay.

\section{3 | RESULTS}

\subsection{Cloning the conserved sequence of CaLPAT2 to construct the RNAi vector}

The conserved region encoding the NHXXXXD box, FP/VEGTR box, and the connecting region in CaLPAT2 mRNA was chosen as the target of RNAi (Figure 2a; Murphy, 2009). The expression levels of the homologues of Arabidopsis LPAT1-5 in C. abyssinica (CaLPAT) were assayed by qPCR (Figure 2b). In comparison with the other CaLPATs,

TABLE 2 The seeds used for FAME GC analysis

\begin{tabular}{lllc} 
Generation & Vector & $\begin{array}{l}\text { Seed } \\
\text { family }\end{array}$ & $\begin{array}{l}\text { Seed } \\
\text { Nr. }\end{array}$ \\
\hline & Wild type & 3 & 60 \\
T1 & CaLPAT2-RNAi & 2 & 60 \\
T1 & BnFAE + LdLPAT & 3 & 100 \\
T1 & BnFAE + LdLPAT + CaFAD2-RNAi & 5 & 120 \\
T1 & BnFAE + LdLPAT + CaFAD2- & 4 & 120 \\
& RNAi + CaLPAT2RNAi & & \\
\end{tabular}

Note. Seed family $\mathrm{Nr}=$ number of seed families chosen for the assay; Seed $\mathrm{Nr}=$ number of seeds from those families analysed by FAME GC. FAME = fatty acid methyl esters; GC = gas chromatography.
CaLPAT2 had the highest expression level that was 7 to 20 folds higher than the others. The expression level of Arabidopsis diacylglycerol acyltransferase 2 homologues (CaDGAT2) in the same period was as same as CaLAPT2. The sequence was cloned by PCR from the cDNA of crambe seed 20 DAF. It was integrated into clone/entry vector pENTR/D-TOPO, of which the success was verified by sequencing. Finally, the target fragment in pENTR/D-TOPO was recombined into the empty pHellsgate 8 vector, to build the CaLPAT-RNAi. The desired RNAi vectors were identified by restriction of Xbal and Xhol, respectively. As shown in Supplementary Figure 1, both of the digestions gave the bands of expected sizes, which indicated the successful construction of the CaLPAT2-RNAi vector.

\section{2 | Transformation of Arabidopsis and crambe with CaLPAT-RNAi}

Arabidopsis (Accession, Columbia) and crambe were transformed with construct CaLPAT2-RNAi using Agrobacterium. There were five independent T0 crambe lines and 20 T1 Arabidopsis lines acquired after Kanamycin selection and confirmed by PCR.

The expression of endogenous LPAT2 in the transgenic plants was downregulated because of the RNAi, which was confirmed by the qPCR. Among the 20 T1 lines of Arabidopsis, the most efficient RNAi effect is shown in Figure 3a. The LPAT2 expression level in the GM plant leaf tissue was about 20-fold lower than the wild type (Student's $t$ test: $p<.01$ ). The phenotypes of shorter silique and seed abortion were observed in parallel with the low expression level of LPAT2 in the T1 Arabidopsis plants (Figure 4).

Compared with the WT, the T0 crambe with the lowest LPAT2 expression was around 50\% decreased in leaf tissue (Student's $t$ test: $p<.01$ ), and 80\% downregulated in developing seeds (Figure 3b). Crambe has only one seed per pod, so abortion of a seed results in empty pods. No difference in seed abortion or seed size between WT plant and the CaLPAT-RNAi transgenic plant was found in this experiment.

\section{3 | Identification of transgenic events of BnFAE + LdLPAT, BnFAE + LdLPAT + CaFAD2-RNAi, and BnFAE + LdLPAT + CaFAD2-RNAi + CaLPAT2- RNAi}

The vectors BnFAE + LdLPAT, BnFAE + LdLPAT + CaFAD2-RNAi, and BnFAE + LdLPAT + CaFAD2-RNAi + CaLPAT2-RNAi were transformed into C. abyssinica. After selection by Kanamycin and verification by PCR using primers of NPTII and VirG, there were three independent TO lines of BnFAE + LdLPAT, eight of BnFAE + LdLPAT + CaFAD2-RNAi, and four of BnFAE + LdLPAT + CaFAD2-RNAi + CaLPAT2-RNAi obtained. The T-DNA insertion number of BnFAE + LdLPAT TO lines was verified by Southern blotting (Figure 5). Of the BnFAE + LdLPAT independent transformants, one had two T-DNA inserts, one had three (or four) T-DNA inserts, and one had more than six T-DNA inserts.

The expression of CaFAD2 and CaLPAT2 was assayed by qPCR in developing seeds (20 DAF) of WT, a T0 line of BnFAE + LdLPAT + CaFAD2-RNAi and two T0 lines of BnFAE + LdLPAT + CaFAD2-RNAi + CaLPAT2-RNAi. In comparison 

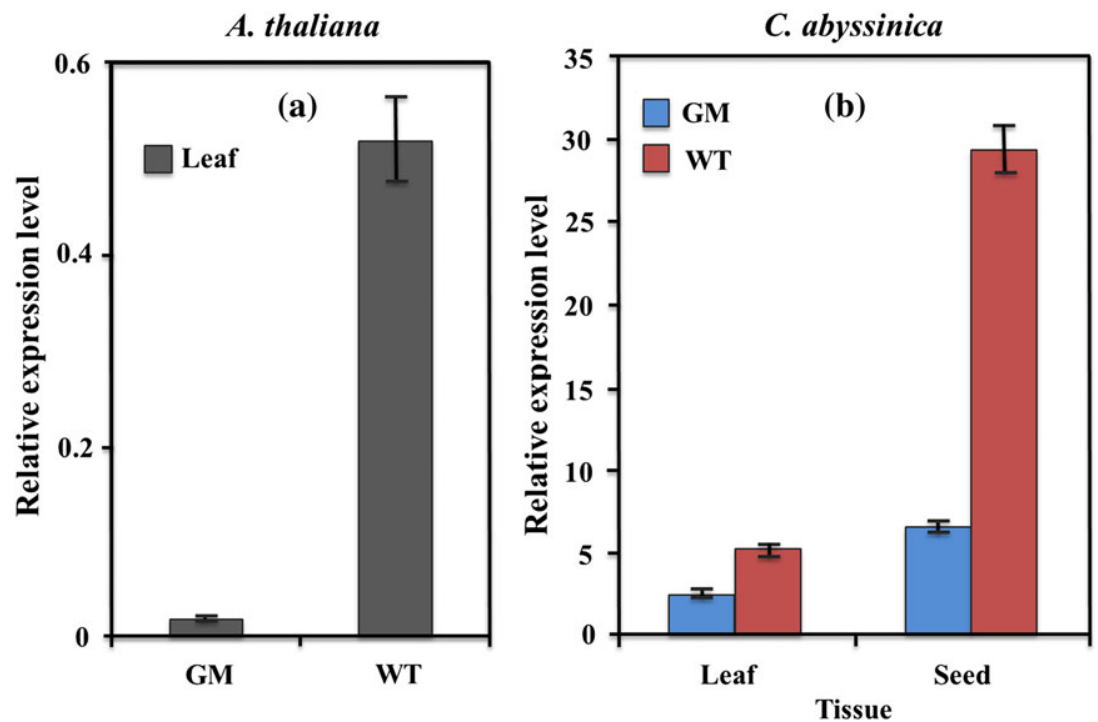

FIGURE 3 Quantitative polymerase chain reaction (qPCR) tests on CaLPAT2-RNAi GM plant materials of Arabidopsis (a) and crambe (b): Endogenous LPAT2 expression levels of the leaf materials from T1 Arabidopsis and T0 crambe plants and developing T1 crambe seeds were analysed by qPCR. The GM lines indicating the highest decrease levels are shown in the charts. The column is the average of repeats, and the bar is standard deviation. The qPCR result of transgene Arabidopsis and crambe with the most efficient RNAi effect is demonstrated in the charts. In comparison with the wild type, the LPAT2 expression of transgene Arabidopsis and crambe was suppressed into significantly lower levels in different tissues (according to Student's $t$ test analysis) [Colour figure can be viewed at wileyonlinelibrary.com]

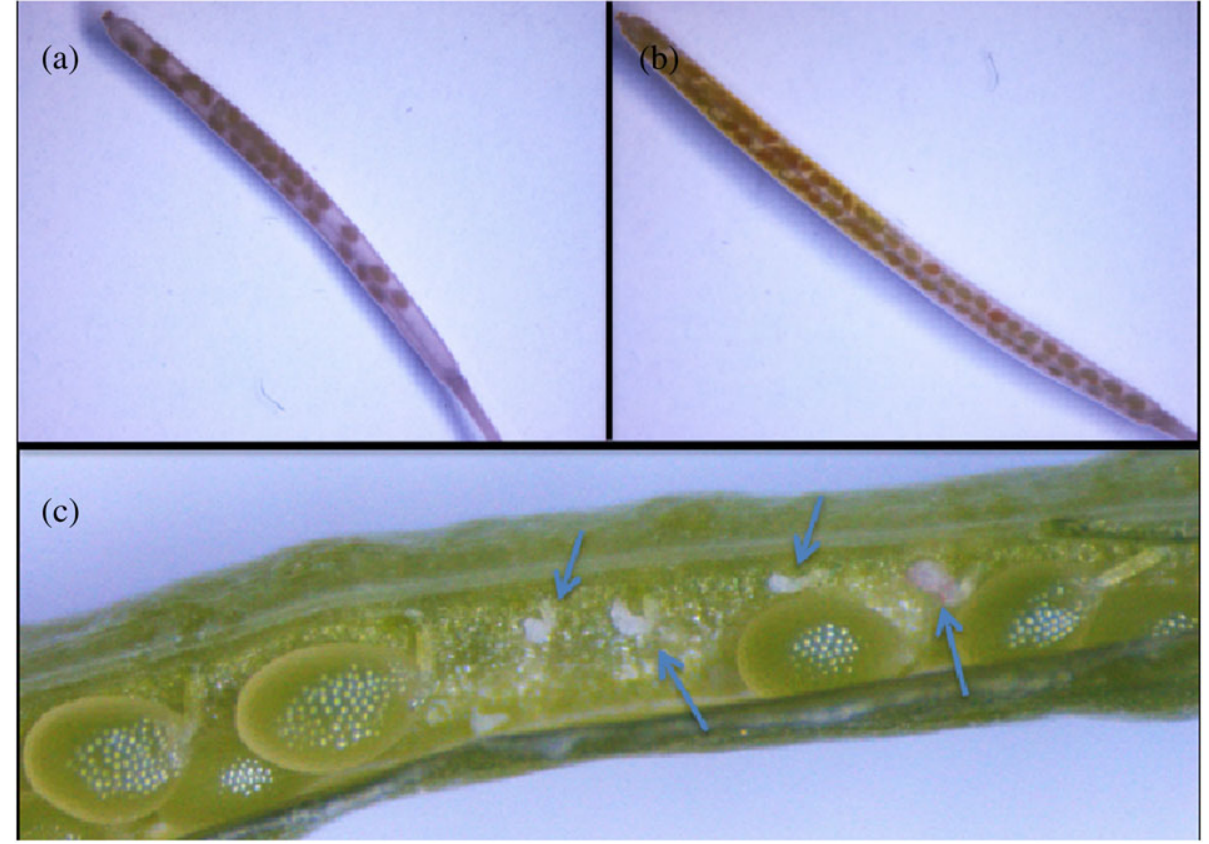

FIGURE 4 The phenotype of LPAT2 knockdown in Arabidopsis by RNAi: The T1 plant of Arabidopsis CaLPAT2-RNAi transformed showed shorter silique (a) than that of the wild type (b). Inside the developing silique, a fraction of the developing seeds were aborted (c, marked by arrows) [Colour figure can be viewed at wileyonlinelibrary.com]

to the WT, the expression of CaFAD2 in the transgenic developing seeds of BnFAE + LdLPAT + CaFAD2-RNAi and BnFAE + LdLPAT + CaFAD2RNAi + CaLPAT2-RNAi was about fourfold to fivefold downregulated
(Figure 6a). The expression of CaLPAT2 was only around fourfold decreased in the developing seeds from BnFAE + LdLPAT + CaFAD2RNAi + CaLPAT2-RNAi (Figure 6b). 


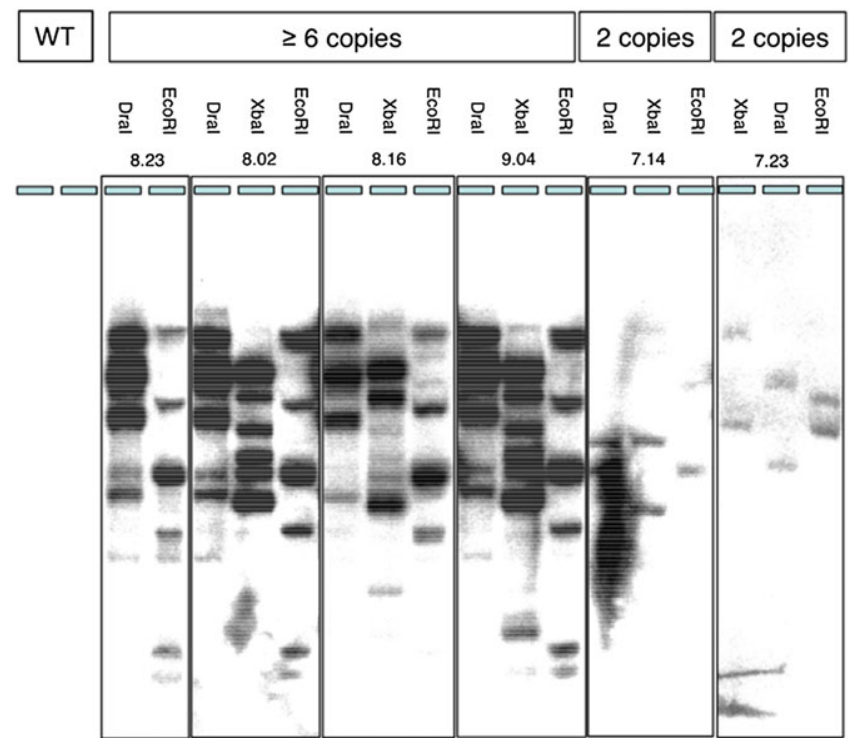

FIGURE 5 Southern blotting analysis of TO crambe plant of BnFAE + LdLPAT transformation: The probe was designed according to NPTII gene, and three restriction enzymes (Dral, Xbal, and EcoRI) were used for DNA digestion. The southern blotting result demonstrated that one line (ID: 9.04) had more than six T-DNA insertions, line 7.23 had two T-DNA insertions, and the T-DNA insertion number of 7.14 was two or three. WT = wild type [Colour figure can be viewed at wileyonlinelibrary.com]

\section{4 | Variation of PUFA content of the T1 seed oil}

According to the crambe seed oil fatty-acid composition, its PUFA consists mainly of linoleic fatty acid (C18:2) and linolenic fatty acid (C18:3). In the WT seed oil, the C18:2 content varied from $6.7 \%$ to $11.2 \%$. The CaLPAT2-RNAi and the CaFAD2-RNAi contained vectors that could downregulate linoleic acid content in seed oil significantly, but the transgenic of BnFAE + LdLPAT had the same C18:2 content as the WT, as showed in Figure 7a. Meanwhile, the linolenic acid content of the transgenic seed was generally significantly decreased. The fourgene combination had the most severe effect, and the linolenic acid content was less than half of the WT. The CaLPAT-RNAi downregulated the C18:3 content to a significantly lower level, similar to BnFAE + LdLPAT + CaFAD2-RNAi.

\section{5 | The variation of erucic acids in the T1 seed oil of transformants}

Based on the qPCR results, seeds from the pHellsgate CaLPAT2-RNAi TO plant with the most significant CaLPAT2 suppression were selected for GC analysis. Compared with wild type, the T1 seed oil had a generally stable and significantly higher level of erucic acid content: $64.5 \%$ on average and ranging from $63.1 \%$ to $66.3 \%$. There were four T1 seed families of BnFAE + LdLPAT + CaFAD2-RNAi + CaLPAT2RNAi assayed. Erucic acid content in single seed oil varied on a large scale. Single seeds with more than $70 \%$ erucic acid in its oil were found in three families; the highest value of single seed was $71.6 \%$. However, the highest erucic acid content, as much as $79.2 \%$, was found in the transgene seeds of BnFAE + LdLPAT + CaFAD2-RNAi.

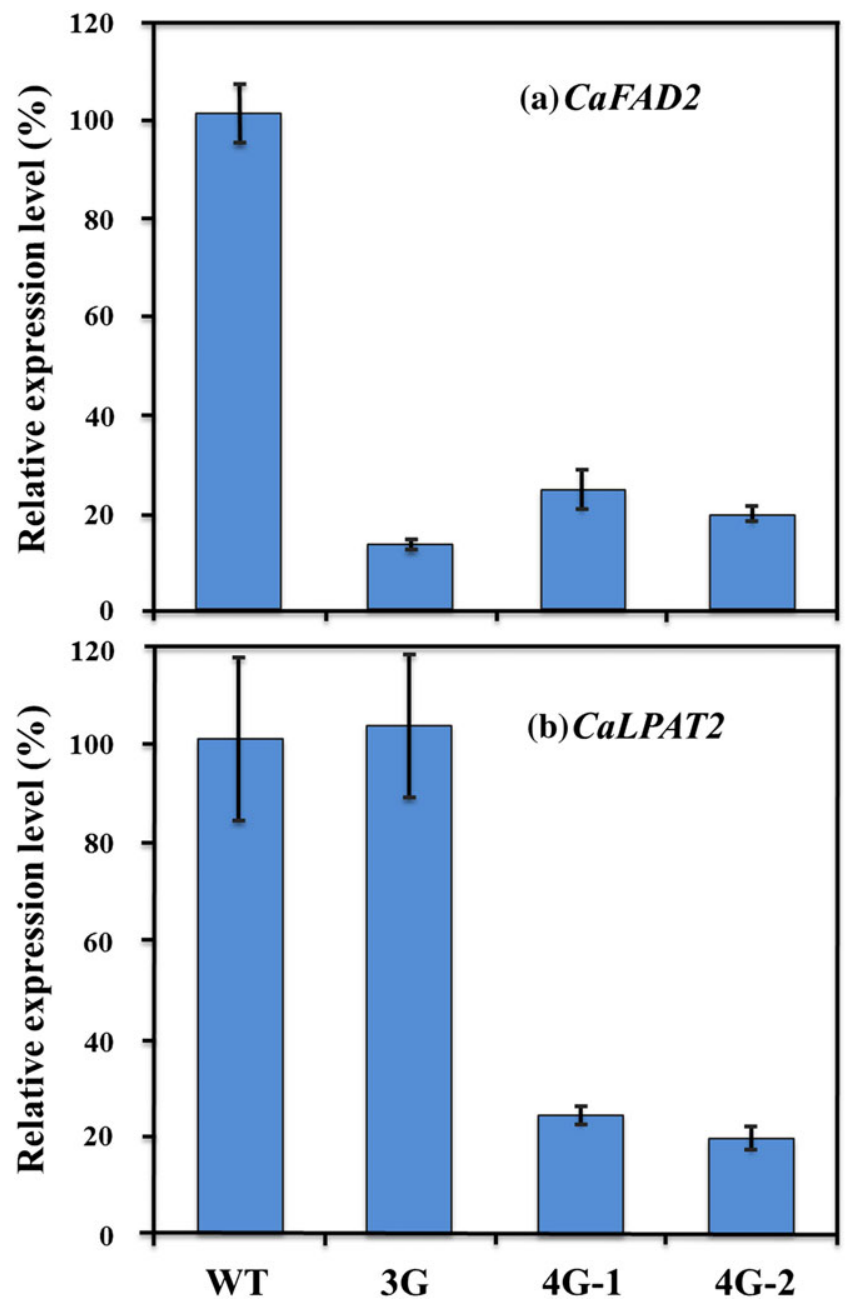

FIGURE 6 Quantitative polymerase chain reaction analysis of the developing GM seeds of BnFAE + LdLPAT + CaFAD2-RNAi and BnFAE + LdLPAT + CaFAD2-RNAi + CaLPAT2-RNAi transformations: The T1 developing seeds of 20 days after flowering were used for this assay. Two TO BnFAE + LdLPAT + CaFAD2-RNAi + CaLPAT2-RNAi plants (4G-1 and 4G-2) and one TO BnFAE + LdLPAT + CaFAD2-RNAi plant (3G) were selected for the test. The wild type (WT) seeds were acquired from the control plant through tissue culture together with the transformed. Panel (a) shows the expression level of CaFAD2; Panel (b) shows the expression level of CaLPAT2 [Colour figure can be viewed at wileyonlinelibrary.com]

Meanwhile, among the transgene seeds of BnFAE + LdLPAT, none showed erucic acid content higher than $66.4 \%$. One-way analysis of variance showed that the erucic acid content in the seeds of CaLPAT2-RNAi and the four-gene and three-gene constructs were significantly higher than those of the WT and two-gene vector. The erucic acid content distribution is shown by the box-blot in Figure 7c.

Previous research showed that introducing BnFAE into the crambe genome might cause a possible cosuppression phenotype of which the oleic content became ultra-high but the erucic acid low ( $\mathrm{Li}$ et al., 2012). A similar phenomenon was also discovered in present research. To avoid the unexpected influence of evaluating the trait associated with CaLPAT2-RNAi, the data of seeds with suppressed erucic acid content lower than the wild type were excluded and not shown here. 

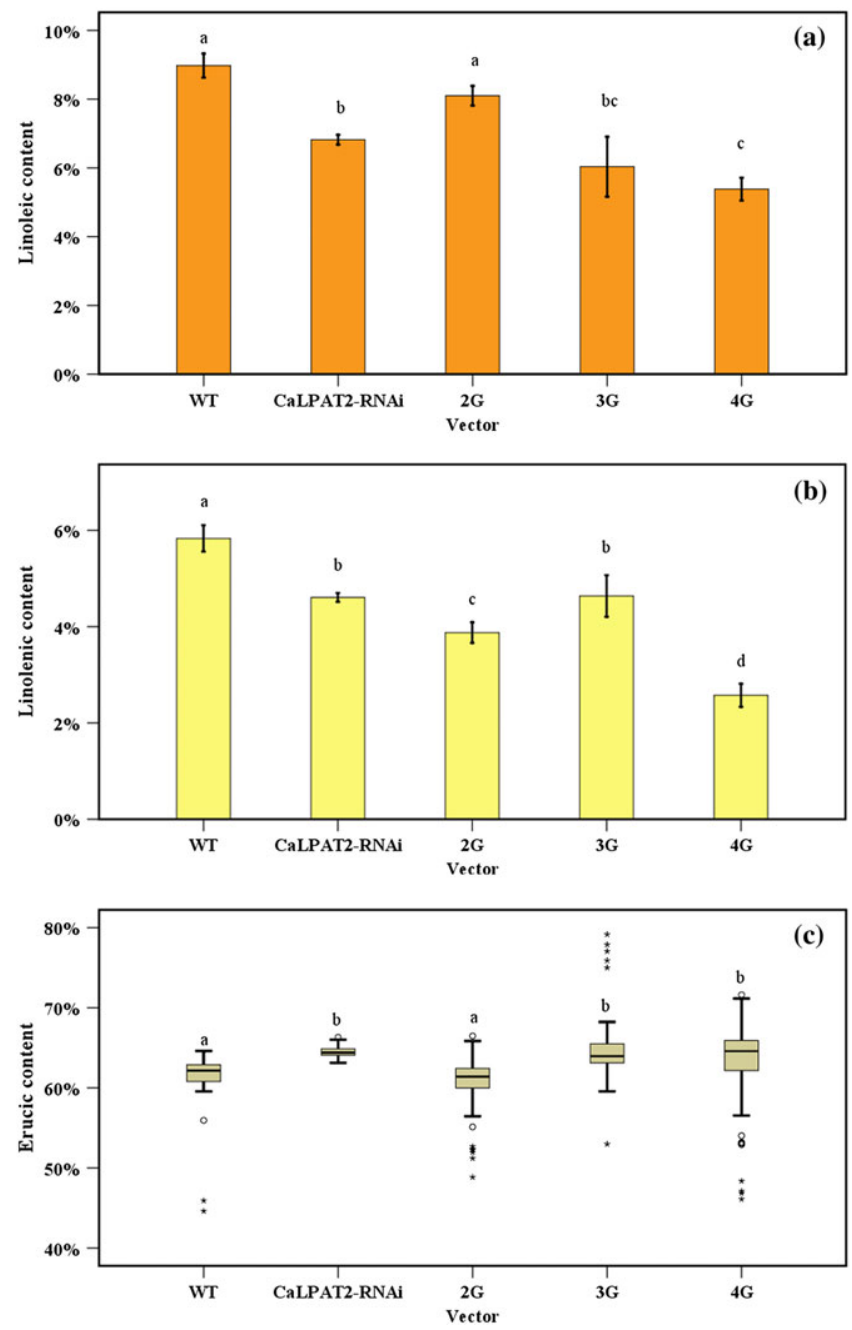

FIGURE 7 Linoleic, linolenic, and erucic acid content of T1 seeds: In crambe seed oil, the main composition of PUFA were linoleic and linolenic acid. They were acknowledged as the major competitors of erucic acid in the fatty acid biosynthesis and accumulation pathways. Linoleic, linolenic, and erucic acid content of T1 seeds are demonstrated in Panels (a), (b), and (c). In Panels (a) and (b), the column is the mean, and the bars are standard deviation; (c) is a boxplot: The letters on the top of bars indicate the significant differences (analysis of variance: Tukey). All of the transgene seeds had lower PUFA accumulated than the wild type (WT). 2G: BnFAE + LdLPAT; 3G: BnFAE + LdLPAT + CaFAD2-RNAi; 4G: BnFAE + LdLPAT + CaFAD2RNAi + CaLPAT2-RNAi [Colour figure can be viewed at wileyonlinelibrary.com]

\section{4 | DISCUSSION}

There are five known LPAT isoforms (LPAT1, 2, 3, 4, and 5) of Arabidopsis (Kim et al., 2005). All except LPAT1 are located on the endoplasmic reticulum. Among the genes encoding LPAT isoforms, LPAT2 always has much higher expression levels in various tissues (callus, inflorescence, leaf, root, and silique) than the others. The present research showed that, in the developing seeds, the LPAT2 homologous gene also had a higher expression level than the others. The present research also indicated that the LPAT2 expression of Arabidopsis and crambe could be suppressed efficiently by the RNAi targeting of the encoding sequence of NHXXXXD box, FP/VEGTR box, and the connecting region in between (Frentzen \& Wolter, 1998). The CaLPAT2-RNAi transformed A. thaliana had an efficiently suppressed LPAT2 expression in leaves and the expected phenotype (shorter pods and a high proportion of seed abortion) was extremely similar to the T-DNA insert mutant (Kim et al., 2005). The transformed C. abyssinica also showed a significantly reduced LPAT2 expression both in leaves and developing seeds but no seed abortion or difference in seed size.

By inserting the palindrome sequence from the CaLPAT2RNAi into the BnFAE + LdLPAT + CaFAD2-RNAi vector, the BnFAE + LdLPAT + CaFAD2-RNAi + CaLPAT2-RNAi vector was constructed. The qPCR analysis on endogenous CaFAD2 and CaLPAT2 gene expression demonstrated that the double-RNAi was functional. The GC analysis also indicated that the T1 seed oil had enhanced erucic acid accumulation (highest value: $71.6 \%$ ) and a suppressed PUFA level. We expected the BnFAE + LdLPAT + CaFAD2-RNAi + CaLPAT2-RNAi transformant seed would have higher erucic acid content than the seeds of all the other transformants. However, the highest value (79.2\%) in the present research was from the BnFAE + LdLPAT + CaFAD2-RNAi transformant. However, a report from Li et al. (2012) showed that transformation of BnFAE + LdLPAT could also result in ultra-high erucic acid content of more than $70 \%$. Considering the results of the present research, the suppression of endogenous LPAT2 may not improve erucic acid content any further in crambe seed oil than the former strategy. Furthermore, Guan, Lager, Li, Stymne, and Zhu (2013) showed that in the developing crambe embryos of BnFAE + LdLPAT transgene, the erucic acid moiety was mainly locked in the phosphate choline (PC) fraction. Hence, the bottleneck was likely between PC and TAG.

The four-gene combination vector did not work as well as expected, despite the extra RNAi targeting on endogenous LPAT2. However, we did find that there were some remarkable traits concerned with CaLPAT2-RNAi. First, it was totally unexpected that CaLPAT2-RNAi alone could optimize the crambe oil composition. It is clear that downregulation of endogenous LPAT2 expression allowed increased carbon flux to go to erucic acid, and less to PUFA, even though the highest erucic acid content of the transgene seeds was $66.4 \%$. It is not clear why this occurred. A hypothesis is that in the developing seed, when the LPAT2 was suppressed by RNAi, other functional LPATs were put in charge of TAG biosynthesis, and their substrate affinities being different to that of LPAT2 led to this fattyacid modulation. Furthermore, the existence of CaLPAT2-RNAi together with BnFAE + LaLPAT + FAD2-RNAi also indicated some special trait in seed oil composition. In comparison with the three-gene combination, the four-gene vector had significantly restrained linolenic fatty acid accumulation. Previously, it has been reported that FAD3RNAi could inhibit linolenic acid deposition in Arabidopsis and crambe seed oil (Li et al., 2015). But, there has been no research ever showing or implying the relationship between PUFA content and LPAT2. In present research, it was significant indeed that the four-gene transformation resulted in more carbon resource deposited into the C22:1 and C18:1 moieties (Figure 8) and lower PUFA, than the WT and the other vectors. This result demonstrates that suppression of endogenous LPAT2 is a new and promising strategy for seed-oil biosynthesis pathway engineering alternatively for improving crambe seed-oil quality and economical value of crambe cultivation. 


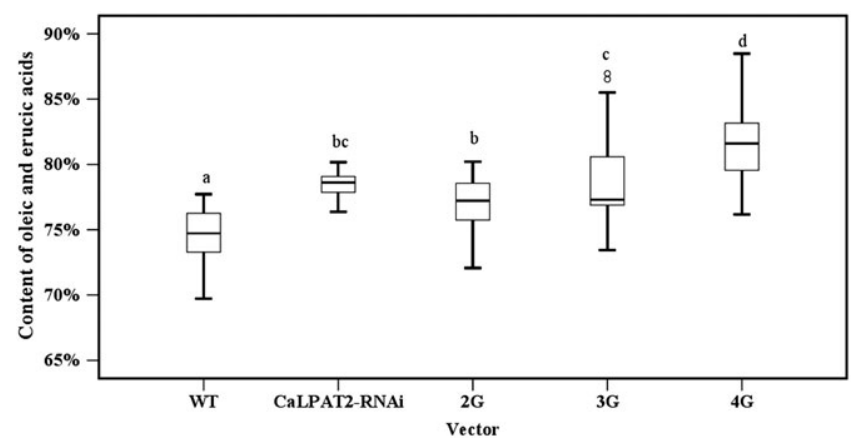

FIGURE 8 The distribution of oleic and erucic acid content: The oleic and erucic acid formed the majority of fatty acids deposited in crambe seed oil. The boxplot shows the influence from the transgene on oleic and erucic acid content in T1 seeds. The letters on the top of bars indicate the significant differences (analysis of variance: Tukey). All of the transgene seeds had lower PUFA accumulated than the wild type (WT). 2G: BnFAE + LdLPAT; 3G: BnFAE + LdLPAT + CaFAD2-RNAi; 4G: BnFAE + LdLPAT + CaFAD2-RNAi + CaLPAT2-RNAi

\section{ACKNOWLEDGMENTS}

This research was funded by the European Union 7th Framework Project "Industrial Crops Producing Added Value Oil for Novel Chemicals", Key Laboratory of Oil Crops in Huanghuaihai Plain, Ministry of Agriculture, P.R. China (HOC1702), Henan Provincial Key Laboratory for Oil Crops Improvement, and Jiangsu Agriculture Science and Technology Innovation Fund [CX(15)1005].

\section{DISCLOSURES}

There is no conflict of interest regarding the paper.

\section{ORCID}

Weicong Qi (D) http://orcid.org/0000-0001-5459-2767

Zhao Zhang (D) http://orcid.org/0000-0002-7323-5500

Hongbo Shao (D) http://orcid.org/0000-0002-3921-5485

Eibertus N. Van Loo (iD http://orcid.org/0000-0003-3738-6368

\section{REFERENCES}

Aldrich, J., \& Cullis, C. (1993). RAPD analysis in flax: Optimization of yield and reproducibility using KlenTaq 1 DNA polymerase, Chelex 100, and gel purification of genomic DNA. Plant Molecular Biology Reporter, 11, 128-141. https://doi.org/10.1007/BF02670471

Bruun, J., \& Matchett, J. (1963). Utilization potential of Crambe abyssinica. Journal of the American Oil Chemists Society, 40, 1-5. https://doi.org/ $10.1007 / \mathrm{bf02645777}$

Cao, Y.-z., Khaik-Cheang, H., \& AHC (1990). Lysophosphatidate acyltransferase in the microsomes from maturing seeds of meadowfoam (Limnanthes alba). Plant Physiology, 94, 1199-1206.

Carlsson, A. S. (2009). Plant oils as feedstock alternatives to petroleum-A short survey of potential oil crop platforms. Biochimie, 91, 665-670. https://doi.org/10.1016/j.biochi.2009.03.021

Cases, S., Smith, S. J., Zheng, Y.-W., Myers, H. M., Lear, S. R., Sande, E., ... Farese, J. (1998). Identification of a gene encoding an acyl CoA: Diacylglycerol acyltransferase, a key enzyme in triacylglycerol synthesis. Proceedings of the National Academy of Sciences, 95, 13018-13023.

Chapman, K. D., \& Ohlrogge, J. B. (2012). Compartmentation of triacylglycerol accumulation in plants. Journal of Biological Chemistry, 287, 2288-2294. https://doi.org/10.1074/jbc.R111.290072
Cheng, J., Salentijn, E. M. J., Huang, B., Krens, F. A., Dechesne, A. C., Visser, R. G. F., \& Loo, E. N. (2013). Isolation and characterization of the omega-6 fatty acid desaturase (FAD2) gene family in the allohexaploid oil seed crop Crambe abyssinica Hochst. Molecular Breeding, 1-15. https://doi.org/10.1007/s11032-013-9886-0

Clough, S. J., \& Bent, A. F. (1998). Floral dip: A simplified method for Agrobacterium-mediated transformation of Arabidopsis thaliana. The Plant Journal, 16, 735-743. https://doi.org/10.1046/j.1365313x.1998.00343.x

Falasca, S. L., Flores, N., Lamas, M. C., Carballo, S. M., \& Anschau, A. (2010). Crambe abyssinica: An almost unknown crop with a promissory future to produce biodiesel in Argentina. International Journal of Hydrogen Energy, 35, 5808-5812. https://doi.org/10.1016/j.ijhydene.2010.02.095

Fowler, J. L. (1991). Interaction of salinity and temperature on the germination of Crambe. Agronomy Journal, 83, 169-172. https://doi.org/ 10.2134/agronj1991.00021962008300010039x

Frentzen, M., \& Wolter, F. P. (1998). Molecular biology of acyltransferases involved in glycerollipid synthesis. In Plant lipid biosynthesis: Fundamentals and agricultural applications.

Guan, R, Lager, I, Li, X, Stymne, S, Zhu, L-H. 2013. Bottlenecks in erucic acid accumulation in genetically engineered ultrahigh erucic acid Crambe abyssinica. Plant Biotechnology Journal: n/a-n/a. https://doi.org/ 10.1111/pbi.12128

Gurr, M. I., Blades, J., Appleby, R. S., Smith, C. G., Robinson, M. P., \& Nichols, B. W. (1974). Studies on seed-oil triglycerides. European Journal of Biochemistry, 43, 281-290. https://doi.org/10.1111/j.14321033.1974.tb03411.x

Han, J., Lühs, W., Sonntag, K., Zähringer, U., Borchardt, D., Wolter, F., ... Frentzen, M. (2001). Functional characterization of $\beta$-ketoacyl-CoA synthase genes from Brassica napus L. Plant Molecular Biology, 46, 229-239. https://doi.org/10.1023/a:1010665121980

Harrison, S., Mott, E., Parsley, K., Aspinall, S., Gray, J., \& Cottage, A. (2006). $A$ rapid and robust method of identifying transformed Arabidopsis thaliana seedlings following floral dip transformation. Plant Methods, 2, 19.

Hu, X., Sullivan-Gilbert, M., Gupta, M., \& Thompson, S. (2006). Mapping of the loci controlling oleic and linolenic acid contents and development of fad2 and fad3 allele-specific markers in canola (Brassica napus L.). Theoretical and Applied Genetics, 113, 497-507. https://doi.org/ 10.1007/s00122-006-0315-1

Hu, Y., Wu, G., Cao, Y., Wu, Y., Xiao, L., Li, X., \& Lu, C. (2009). Breeding response of transcript profiling in developing seeds of Brassica napus. BMC Molecular Biology, 10, 49.

Huang, A. H. (1996). Oleosins and oil bodies in seeds and other organs. Plant Physiology, 110, 1055-1061.

Jadhav, A., Katavic, V., Marillia, E.-F., Michael Giblin, E., Barton, D. L., Kumar, A., ... Taylor, D. C. (2005). Increased levels of erucic acid in Brassica carinata by co-suppression and antisense repression of the endogenous FAD2 gene. Metabolic Engineering, 7, 215-220. https:// doi.org/10.1016/j.ymben.2005.02.003

Kennedy, E. P. (1961). Biosynthesis of complex lipids. Federation Proceedings, 20, 934-940.

Khaik-Cheang, H., \& AHC (1989). Lysophosphatidate acyltransferase activities in the microsomes from palm endosperm, maize scutellum, and rapeseed cotyledon of maturing seeds. Plant Physiology, 91, 1288-1295.

Kim, H. U., Li, Y., \& Huang, A. H. C. (2005). Ubiquitous and endoplasmic reticulum-located lysophosphatidyl acyltransferase, LPAT2, is essential for female but not male gametophyte development in Arabidopsis. The Plant Cell Online, 17, 1073-1089. https://doi.org/10.1105/ tpc.104.030403

Kocsis, M. G., Weselake, R. J., Eng, J. A., Furukawa-Stoffer, T. L., \& Pomeroy, M. K. (1996). Phosphatidate phosphatase from developing seeds and microspore-derived cultures of Brasssica napus. Phytochemistry, 41, 353-363.

Kuo, T. M., \& Gardner, H. W. (2002). Lipid biotechnology. New York·Basel: Marcel Dekker, Inc. 
Lassner, M. W., Levering, C. K., Davies, H. M., \& Knutzon, D. S. (1995). Lysophosphatidic acid acyltransferase from meadowfoam mediates insertion of erucic acid at the sn-2 position of triacylglycerol in transgenic rapeseed oil. Plant Physiology, 109, 1389-1394.

Laurent, P., \& Huang, A. H. C. (1992). Organ- and development-specific acyl coenzyme A lysophosphatidate acyltransferases in palm and meadowfoam. Plant Physiology, 99, 1711-1715.

Lazo, G. R., Stein, P. A., \& Ludwig, R. A. (1991). A DNA transformationcompetent Arabidopsis genomic library in agrobacterium. Nat Biotech, 9, 963-967.

Li, R., Yu, K., \& Hildebrand, D. (2010). DGAT1, DGAT2 and PDAT expression in seeds and other tissues of epoxy and Hydroxy fatty acid accumulating plants. Lipids, 45, 145-157. https://doi.org/10.1007/ s11745-010-3385-4

Li, X., Mei, D., Liu, Q., Fan, J., Singh, S., Green, A., ... Zhu, L.-H. (2015). Down-regulation of crambe fatty acid desaturase and elongase in Arabidopsis and crambe resulted in significantly increased oleic acid content in seed oil. Plant Biotechnology Journal, n/a-n/a. https://doi. org/10.1111/pbi.12386

Li, X., van Loo, E. N., Gruber, J., Fan, J., Guan, R., Frentzen, M., ... Zhu, L.-H. (2012). Development of ultra-high erucic acid oil in the industrial oil crop Crambe abyssinica. Plant Biotechnology Journal, 10, 862-870. https://doi.org/10.1111/j.1467-7652.2012.00709.x

Mietkiewska, E., Brost, J. M., Giblin, E. M., Barton, D. L., \& Taylor, D. C. (2007). Cloning and functional characterization of the fatty acid elongase 1 (FAE1) gene from high erucic Crambe abyssinica cv. Prophet. Plant Biotechnology Journal, 5, 636-645.

Murata, N., \& Tasaka, Y. (1997). Glycerol-3-phosphate acyltransferase in plants. Biochimica et Biophysica Acta, 1348, 10-16.

Murphy, D. J. (2009). Plant lipids: Biology, utilisation and manipulation. Blackwell Publishing Ltd.

Murphy, D. J., \& Vance, J. (1999). Mechanisms of lipid-body formation. Trends in Biochemical Sciences, 24, 109-115.

Okuley, J., Lightner, J., Feldmann, K., Yadav, N., Lark, E., \& Browse, J. (1994). Arabidopsis FAD2 gene encodes the enzyme that is essential for polyunsaturated lipid synthesis. The Plant Cell Online, 6, 147-158. https://doi.org/10.1105/tpc.6.1.147

Paulose, B., Kandasamy, S., \& Dhankher, O. P. (2010). Expression profiling of Crambe abyssinica under arsenate stress identifies genes and gene networks involved in arsenic metabolism and detoxification. BMC Plant Biology, 10, 108.

Qi, W., Tinnenbroek-Capel, I. E., Schaart, J. G., Huang, B., Cheng, J., Visser, R. G., ... Krens, F. A. (2014). Regeneration and transformation of Crambe abyssinica. BMC Plant Biology, 14, 235.
Routaboula, J.-M., Benningb, C., Bechtoldc, N., Cabochea, M., \& Lepinieca, L. (1999). The TAG1 locus of Arabidopsis encodes for a diacylglycerol acyltransferase. Plant Physiology and Biochemistry, 37, 831-840.

Rudloff, E., \& Wang, Y. (2011). Crambe. In C. Kole (Ed.), Wild crop relatives: Genomic and breeding resources (pp. 97-116). Berlin Heidelberg: Springer.

Schierholt, A., Becker, H. C., \& Ecke, W. (2000). Mapping a high oleic acid mutation in winter oilseed rape (Brassica napus L.). Theoretical and Applied Genetics, 101, 897-901. https://doi.org/10.1007/ s001220051559

Soupene, E., Fyrst, H., \& Kuypers, F. A. (2007). Mammalian acyl-CoA: Lysophosphatidylcholine acyltransferase enzymes. Proceedings of the National Academy of Sciences, 105, 88-93.

Vargas-Lopez, J. M., Wiesenborn, D., Tostenson, K., \& Cihacek, L. (1999). Processing of crambe for oil and isolation of erucic acid. Journal of the American Oil Chemists' Society, 76, 801-809. https://doi.org/10.1007/ s11746-999-0069-4

Vasconcelos, A. C. F. D., Chaves, L. C. H. G., Souza, F. G., Gheyi, H. R., \& Fernandes, J. D. (2015). Salinity effects on development and productivity of Crambe (Crambe abyssinica) under greenhouse conditions. American Journal of Plant Sciences, 06(07), 9. https://doi.org/10.4236/ ajps.2015.67091

Wesley, S., Liu, Q., Wielopolska, A., Ellacott, G., Smith, N., Singh, S., \& Helliwell, C. (2003). Custom knock-outs with hairpin rna-mediated gene silencing. In E. Grotewold (Ed.), Plant functional genomics (pp. 273-286). Humana Press.

White, G. A., \& Higgins, J. J. (1966). Culture of Crambe: A new industrial oilseed crop. Agricultural Research Service, U.S. Dept. of Agriculture: Washington U.S.

Zheng, Z., \& Zou, J. (2001). The initial step of the Glycerolipid pathway: Identification of glycetol 3-phosphate/dihydroxyacetone phosphate dual substrate acyl transferase in Saccharomyces cerevisiae. The Journal of Biological Chemistry, 276, 41710-41716.

\section{SUPPORTING INFORMATION}

Additional Supporting Information may be found online in the supporting information tab for this article.

How to cite this article: Qi W, Tinnenbroek-Capel IEM, Salentijn EMJ, et al. Genetically engineering Crambe abyssinica -A potentially high-value oil crop for salt land improvement. Land Degrad Dev. 2018;29:1096-1106. https://doi.org/ 10.1002/ldr.2847 